DOI: 10.19112/2413-6174-2021-S1-02

\title{
ВЛИЯНИЕ УЛЬТРАДИСПЕРСНЫХ КОРМОВЫХ ДОБАВОК, ПРОБИОТИЧЕСКИХ ШТАММОВ И ИХ КОМПЛЕКСОВ НА СОДЕРЖАНИЕ ЭССЕНЦИАЛЬНЫХ МИКРОЭЛЕМЕНТОВ В ОРГАНИЗМЕ КАРПА
}

\author{
А.Е. Аринжанов*, Е.П. Мирочникова, А.Н. Сизенцов, Ю.В. Килякова
}

Оренбургский государственный университет, 460013 г. Оренбург, пр. Победы 13

*e-mail: arin.azamat@mail.ru

РЕЗЮМЕ. В последнее время возрастает интерес к альтернативным кормовым добавкам, таким как биологически активные вещества и ультрадисперсные частицы эссенциальных элементов. Представлены данные сравнительного анализа степени влияния пробиотического штамма B. subtilis ВКПМ В-10641, УДЧ Сu+Zn и их комбинированного действия на рост и элементный статус карпа. Полученные данные свидетельствуют о положительной динамике на фоне применения исследуемых добавок как для повышения продуктивности рыб, так и распределения эссенциальных элементов. Наиболее перспективным является использование комбинации исследуемых стимуляторов роста (пробиотический препарат и УДЧ $\mathrm{Cu}+\mathrm{Zn}$ ) с позиции повышения живой массы и увеличения ключевых эссенциальных элементов в организме рыб.

КЛЮЧЕВЫЕ СЛОВА: наночастицы, пробиотические штаммы, эссенциальные элементы.

\section{INFLUENCE OF ULTRADISPERSED FEED ADDITIVES, PROBIOTIC STRAINS AND THEIR COMPLEXES ON THE CONTENT OF ESSENTIAL TRACE ELEMENTS IN THE CARP BODY}

\author{
A.E. Arinzhanov*, E.P. Miroshnikova, A.N. Sizentsov, Y.V. Kilyakova \\ Orenburg State University, 460013, Orenburg, Pr. Pobedy 13 \\ *e-mail: arin.azamat@mail.ru
}

ABSTRACT. Recently, there has been increasing interest in alternative feed additives such as biologically active substances and ultradisperse particles of essential elements. Our work presents the comparative analysis data of the influence degree of the probiotic strain B. subtilis RCIM B-10641, UDP $\mathrm{Cu}+\mathrm{Zn}$ and their combined effect on the carp growth and elemental status. The data obtained indicate the positive dynamics of productivity against the background of the additives use both to increase fish productivity and to distribute essential elements. The most promising is the use of a combination of the studied growth stimulants (probiotic preparation and UDP $\mathrm{Cu}+\mathrm{Zn}$ ) from the standpoint of increasing live weight and the key essential elements in fish body.

KEYWORDS: nanoparticles, probiotic strains, essential elements.

\section{ВВЕДЕНИЕ}

Потребности животных в основных элементах питания обеспечиваются путем включения в рацион различных кормовых добавок.

Цель исследования - провести сравнительный анализ степени влияния пробиотического штамма B. subtilis, ультрадисперсных частиц (УДЧ) $\mathrm{Cu}+\mathrm{Zn}$ и их комбинированного действия на рост и элементный статус карпа.

\section{МАТЕРИАЛЫ И МЕТОДЫ}

Для реализации, поставленной цели исследования в работе были использованы пробиотический препарат Ветом 1.1. (B. subtilis ВКПМ В-10641), синтезированные плазмохимическим методом УдЧ $\mathrm{Cu}+\mathrm{Zn}(40 \%$ из меди и 60\% из цинка). Для оценки степени влияния исследуемых добавок были сформированы четыре экспериментальные группы пар-аналогов, контрольная интактная группа и три опытных: $\mathrm{O}_{1}-$ с добавлением пробиотического препарата в дозировке 25 мг/кг корма, $\mathrm{O}_{2}-\mathrm{У} Д Ч ~ \mathrm{Cu}+\mathrm{Zn}$ в дозировке 2,84 мг/кг корма, О 3 - комбинация исследуемых добавок в указанных концентрациях. 
Продолжительность эксперимента составила 45 суток. Исследование элементного состава биосубстратов проводилось атомно-эмиссионным и масс-спектральным методами.

\section{РЕЗУЛЬТАТЫ И ОБСУЖДЕНИЯ}

Полученные экспериментальные данные свидетельствуют о выраженном биологически активном действии используемых УДЧ $\mathrm{Cu}+\mathrm{Zn}$ как индивидуально, так и в комплексе с пробиотическим штаммом B. subtilis, о чем свидетельствует существенное увеличение живой массы тела в группах $\mathrm{O}_{2}$ и $\mathrm{O}_{3}$ на 2,91 и $13,22 \%(p \leq 0,01)$, в то время как в группе $\mathrm{O}_{1}$ регистрируются более низкие значения живой массы тела на $16,21 \%(p \leq 0,01)$ по отношению к интактной группе. Анализ структурного распределения эссенциальных элементов (таблица) свидетельствует о выраженном достоверно значимом увеличении $\mathrm{Cu}$

$(p \leq 0,01), \mathrm{Fe}(p \leq 0,001), \mathrm{Mn}(p \leq 0,01), \mathrm{Ni}(p \leq 0,01), \mathrm{Si}(p \leq 0,001)$ и $\mathrm{Zn}(p \leq 0,001)$ на фоне применения УдЧ $\mathrm{Cu}+\mathrm{Zn}$, что связано с интенсификацией обменных процессов (Xin et al., 2013; Sizova et al., 2018).

\section{ВЫВОДЫ}

Введение в рацион комбинированного комплекса УдЧ $\mathrm{Cu}+\mathrm{Zn}$ и пробиотика позволяет достоверно значимо увеличить содержание $\mathrm{Fe}(p \leq 0,01), \mathrm{Mn}(p \leq 0,05)$ и $\mathrm{Ni}(p \leq 0,05)$ по отношению к интактной группе. Однако следует отметить, что введение в рацион транзиторного пробиотического штамма негативно влияет на уровень содержания большинства исследуемых элементов в организме экспериментальных животных.

Таблица. Содержание эссенциальных и условно-эсенциальных микроэлементов в организме рыбы на момент завериения эксперимента, мкг/2

\begin{tabular}{|c|c|c|c|c|}
\hline \multirow{2}{*}{ Элемент } & \multicolumn{4}{|c|}{ Группа } \\
\cline { 2 - 5 } & $\mathrm{K}_{0}$ & $\mathrm{O}_{1}$ & $\mathrm{O}_{2}$ & $\mathrm{O}_{3}$ \\
\hline $\mathrm{Co}$ & $0,01 \pm 0,01$ & $0,02 \pm 0,01$ & $0,02 \pm 0,007$ & $0,02 \pm 0.009$ \\
\hline $\mathrm{Cr}$ & $0,06 \pm 0,01$ & $0,04 \pm 0,003^{* *}$ & $0,07 \pm 0,06$ & $0,04 \pm 0.003$ \\
\hline $\mathrm{Cu}$ & $1,17 \pm 0,10$ & $0,75 \pm 0,005^{* *}$ & $1,45 \pm 0,07 * *$ & $16,70 \pm 0,20^{* *}$ \\
\hline $\mathrm{Fe}$ & $15,60 \pm 0,20$ & $19,90 \pm 0,10^{* *}$ & $18,20 \pm 0,076^{* * *}$ & $0,12 \pm 0,08$ \\
\hline $\mathrm{I}$ & $0,16 \pm 0,10$ & $0,16 \pm 0,10$ & $0,17 \pm 0,05$ & $0,005 \pm 0,003$ \\
\hline $\mathrm{Li}$ & $0,003 \pm 0,002$ & $0,01 \pm 0,007$ & $0,02 \pm 0,001$ & $1,46 \pm 0,20 *$ \\
\hline $\mathrm{Mn}$ & $0,61 \pm 0,20$ & $0,92 \pm 0,08$ & $1,95 \pm 0,15^{* *}$ & $0,51 \pm 0,10^{*}$ \\
\hline $\mathrm{Ni}$ & $0,20 \pm 0,10$ & $0,39 \pm 0,20$ & $0,63 \pm 0,05 * *$ & $0,11 \pm 0,04$ \\
\hline $\mathrm{Se}$ & $0,12 \pm 0,10$ & $0,12 \pm 0,08$ & $0,12 \pm 0,03$ & $10,6 \pm 0,10^{* * *}$ \\
\hline $\mathrm{Si}$ & $13,80 \pm 0,06$ & $8,90 \pm 0,20 * * *$ & $20,70 \pm 0,2 * * *$ & $0,04 \pm 0,03$ \\
\hline $\mathrm{V}$ & $0,02 \pm 0,01$ & $0,04 \pm 0,03$ & $0,06 \pm 0,05$ & $17,20 \pm 0,10^{* *}$ \\
\hline $\mathrm{Zn}$ & $17,60 \pm 0,20$ & $15,50 \pm 0,20^{* *}$ & $24,60 \pm 0,5^{* * *}$ & \\
\hline
\end{tabular}

П р и м е ч а н и е : $*-p \leq 0,05 ; * * p \leq 0,01, * * * p \leq 0,001$, по отношению к контрольным значениям.

\section{Сиисок литературы / References}

1. Sizova E.A., Miroshnikov S.A., Lebedev S.V., Levakhin Y.I., Babicheva I.A., Kosilov V.I. Comparative tests of ultradisperse alloy, salts and organic forms of $\mathrm{Cu}$ and $\mathrm{Zn}$ as sources of trace elements in the feeding of broiler chickens. Agricultural Biology. 2018, 53(2):393-403.

2. Xin W., Xugang S., Xie C., Li J., Hu J., Yin Y.L., Deng Z.Y. The acute and chronic effects of monosodium l-glutamate on serum iron and total iron-binding capacity in the jugular artery and vein of pigs. Biol. Trace. Elem. Res. 2013, 153:191-195. 